\title{
NATURAL HISTORY OF PERIANAL CROHN'S DISEASE: LONG-TERM FOLLOW-UP OF A POPULATION-BASED COHORT
}

Short title : Natural history of perianal Crohn's disease

Charlène BROCHARD ${ }^{1}$, Marie-Laure RABILLOUD ${ }^{2}$, Stéphanie HAMONIC ${ }^{3}$, Emma BAJEUX $^{3}$, Maël PAGENAULT ${ }^{2}$, Alain DABADIE ${ }^{4}$, Agathe GERFAUD ${ }^{5}$, Jean-François VIEL $^{3}$, Isabelle TRON ${ }^{6}$, Michel ROBASZKIEWICZ ${ }^{7}$, Jean-François BRETAGNE ${ }^{2}$, Laurent SIPROUDHIS $^{1}$, Guillaume BOUGUEN ${ }^{1}$ (Groupe ABERMAD)

1 CHU Rennes, Univ Rennes, INSERM, CIC1414, Institut NUMECAN (Nutrition Metabolism and Cancer), F-35000 Rennes, France

${ }^{2}$ CHU Rennes, Univ Rennes, F-35000 Rennes, France

${ }^{3}$ Department of Public Health, University Hospital of Pontchaillou, Rennes, France

${ }^{4}$ CHU Rennes, INRAe, INSERM, Univ Rennes, Institut NUMECAN (Nutrition Metabolism and Cancer), F-35000 Rennes, France

${ }^{5}$ Paediatric Unit, University Hospital, Rennes, France

${ }^{6}$ Observatoire Regional De Santé Bretagne, Rennes, France.

${ }^{7}$ CHU Brest, Univ Brest, F-29000 Brest, France

\section{Correspondence to:}

Guillaume Bouguen

Service des Maladies de l'Appareil Digestif

2 rue Henri le Guillou

35033 Rennes cedex, FRANCE

Telephone (0033)-2-99-28-43-17/Fax (0033)-2-99-28-41-89

Email: guillaume.bouguen@chu-rennes.fr

\section{Competing interests:}

Guillaume BOUGUEN received lecture fees from Abbvie, Ferring, MSD, Takeda and Pfizer and consultant fees from Takeda, Janssen

Laurent SIPROUDHIS received lecture fees from Abbvie, Amgen, Ferring, Janssen, MSD, Takeda and consultant fees from Takeda

Charlène BROCHARD received lecture fees from IPSEN 
Stéphanie HAMONC, Maël PAGENAULT, Agathe GERFAUD, Alain DABADIE, JeanFrançois VIEL, Isabelle TRON, Michel ROBASZKIEWICZ, Jean-François BRETAGNE, Marie-Laure RABILLOUD and Emma BAJEUX declare no conflict of interest

Acknowledgments: All physicians who included patients in the ABERMAD registry particularly to Etienne Cruchant, Jean-Luc Alexandre et Jacques-Arnaud Seyrig members of the scientific committee of ABERMAD.

Contributors:_MLR, MP, AD, IT, MR, AG, LS performed the research; EB, JFV, JFB, LS and GB designed the research study; SH and GB performed statistical analyses; CB, EB et JB analysed the data; $\mathrm{CB}$ and GB wrote the paper; All authors approved the final version the final version of the manuscript.

Funding:_This work received a grant from ABBVIE, Rungis, France

Guarantor of the article: Guillaume BOUGUEN

Word count (including main text, references, table and figure legends): 3483 words. 


\section{ABSTRACT $(\mathbf{n}=250)$}

\section{Background and aims}

The natural history of perianal Crohn's disease (PCD) remains poorly described and is mainly based on retrospective studies from referral centres. The aim of this study was to assess the incidence, outcomes and predictors of the onset of PCD.

\section{Methods}

All incident cases of patients diagnosed with possible CD were prospectively registered from 1994 to 1997 in Brittany, a limited area in France. At diagnosis, the clinical features of perianal disease were recorded. All patient charts were reviewed from the diagnosis to the last clinic visit in 2015.

\section{Results}

Among the 272 out of 331 incident CD patients followed up, 51 (18.7\%) patients had PCD at diagnosis. After a mean follow-up of 12.8 years, 93 (34\%) patients developed PCD. The cumulative probabilities of perianal CD occurrence were $22 \%, 29 \%$, and $32 \%$ after 1 year, 5 years, and 10 years, respectively. The cumulative probabilities of anal ulceration were $14 \%$, and $19 \%$ after 1 year and 10 years, respectively. Extraintestinal manifestations were associated with the occurrence of anal ulceration. The cumulative probabilities of fistulizing PCD were $11 \%, 16 \%$, and $19 \%$ after 1 year, 5 years, and 10 years, respectively. Extraintestinal manifestations, rectal involvement and anal ulceration were predictors of fistulizing PCD. The cumulative probability of developing anal stricture was $4 \%$ after 10 years.

\section{Conclusions}

PCD is frequently observed during CD, in approximately one-third of patients. These data underline the need for targeted therapeutic research on primary perianal lesions (proctitis, anal ulceration) to avoid the onset of fistulizing perianal disease.

Keywords: Perianal Crohn's disease, population based, outcomes, natural history 


\section{INTRODUCTION}

Crohn's disease (CD) is a chronic inflammatory disease whose natural history is characterized by periods of remission and relapse with a heterogeneous disease course ${ }^{1}$. Perianal CD encompasses a wide range of entities ${ }^{2}$, including non-fistulizing (fissures, ulcers and strictures) and fistulizing lesions (fistulas, abscesses and rectovaginal fistulas). It is now well established that perianal $\mathrm{CD}$ is a predictive factor for a disabling disease course ${ }^{3-6}$. More recently, several studies have shown that perianal CD drastically impairs these patients' social and sexual life and impairs quality of life $\mathrm{e}^{7-9}$.

The treatment of both fistulizing and non-fistulizing anal disease remains a challenge in clinical practice. Despite a multidisciplinary approach including anti-TNF treatment and surgeries, perianal $\mathrm{CD}$ is still difficult to cure, with common recurrences that may still lead to the need for proctectomy with definitive stoma for 8 to $40 \%$ of cases ${ }^{10-12}$.

Although perianal involvement was documented as a possible manifestation of CD in $1965^{13}$, few studies have been conducted, and these studies are mostly descriptive or retrospective and focused on perianal fistula that precluded a comprehensive view of perianal $\mathrm{CD}^{14-16}$. Up to $17 \%$ of patients might present with isolated perianal lesions before the diagnosis of $\mathrm{CD}^{5,14}$. The reported cumulative incidence after the diagnosis of CD ranged from $13 \%$ to $30 \%{ }^{4,14,15}$. Data related to non-fistulizing anal disease are often lacking ${ }^{17}$. Superficial fissures and cavitating ulcers may constitute 21 to $35 \%$ and 5 to $10 \%$ of perianal lesions, respectively ${ }^{18-22}$. Anorectal strictures were noted in $9 \%$ to $22 \%$ of patients in referral centre studies ${ }^{19,20}$. These data remain controversial due to the study designs and lack of long-term follow-up. Improved knowledge of the natural history of perianal $\mathrm{CD}$ is thus emergently required to improve the management of $\mathrm{CD}$ and to prevent the onset of perianal $\mathrm{CD}$, particularly perianal fistula. 
The aims of this study were therefore to assess the natural disease course of perianal CD and to identify factors associated with the development of perianal $\mathrm{CD}$ in a population-based cohort.

\section{METHODS}

\section{THE ABERMAD REGISTRY}

The ABERMAD registry included all incident CD cases between 1994 and 1997 in a large administrative area of western France (Brittany), with almost 3259700 inhabitants representing $4.6 \%$ of the national French population. The Brittany is divided into four departments: Côtes d'Armor, Finistère, Morbihan and Ille et Vilaine. Only patients who resided in the defined study area at the time of diagnosis of their disease were included.

The establishment of the ABERMAD registry was carried out according to that of the EPIMAD register as described elsewhere ${ }^{23-25}$. Briefly, adult and paediatric gastroenterologists $(n=139)$ of Brittany practising in the private or public sector prospectively referred all patients consulting for symptoms compatible with inflammatory bowel disease for the first time between 1994 and 1997. An interviewer practitioner completed a standard questionnaire for each patient at the gastroenterologist's consulting room.

The main collected data were age, sex, year of diagnosis, time between the onset of symptoms and diagnosis, and clinical, endoscopic, radiological and histological findings at the time of referral by the gastroenterologist. Endoscopic and radiological findings were prospectively collected at diagnosis. Data from colonoscopy, upper gastrointestinal endoscopy, small bowel transit and barium enema were gathered prospectively at diagnosis. A panel of four expert gastroenterologists reviewed each case independently. They assigned a diagnosis of definite, probable or possible $\mathrm{CD}$, ulcerative colitis, unclassifiable chronic colitis or acute colitis according to the validated Lennard-Jones criteria ${ }^{26}$.

\section{STUDY POPULATION}

For the purpose of the study, only patients with a definite diagnosis of CD were included. From 1994 to 1997, 272 out of 331 patients with a probable or definite diagnosis of CD in the ABERMAD registry and had a follow-up constituted the study population. Data were extracted from the files of gastroenterologists and from hospital medical records. An interviewer collected the extracted data with standardized questionnaires specifically designed for the study from date of CD diagnosis until the last follow-up or date of the last medical record. All charts of the patients were reviewed between 2014 and 2015 to assess the longterm outcomes of the cohort. 


\section{DESCRIPTION OF COLLECTED DATA}

The following data were collected: family history of inflammatory bowel disease, CD location, disease behaviour according to the Montreal classification ${ }^{27}$, and extraintestinal manifestations. An upper gastrointestinal location (L4) could be associated with an ileal (L1), colonic (L2) or ileocolonic (L3) location. Rectal involvement was differentiated. Perianal lesions were described at CD diagnosis as follows: presence or absence of anal fistula, anal ulceration, and anal stricture. Other non-specific Crohn's perianal lesions were not considered, such as haemorrhoids and skin tags. The outcome of the diagnosed perianal disease and the occurrence of new perineal lesions during the follow-up were retrieved from the patient charts according to the main items of the Hughes classification (presence or absence of ulceration, fistula, stricture $)^{28}$. Anal surgeries were recorded separately. All treatments during the study period were recorded, including the use of 5-aminosalicylates (5ASA), corticosteroids (oral and topical steroids), purines (azathioprine, 6-mercaptopurine), methotrexate (MTX), and antitumour necrosis factor (TNF) therapies (infliximab [IFX] and adalimumab $[\mathrm{ADA}])$. All hospitalizations related to $\mathrm{CD}$ were retrieved from the follow-up records. The study was approved by the ethics committee $\left(\mathrm{n}^{\circ} 13.64\right)$. All authors had access to the study data and reviewed and approved the final manuscript.

\section{STATISTICAL ANALYSIS}

A descriptive analysis of the population study was conducted, specifying the baseline demographic, clinical, and endoscopic characteristics. The quantitative data are expressed as medians with IQRs (interquartile ranges), and the qualitative data are expressed as numbers and percentages. Kaplan-Meier survival curves were plotted for variables of interest with censored data. Variables of interest were the onset of any perianal lesion, perianal ulceration, perianal fistula, or perianal stricture at diagnosis or during the follow-up. Factors potentially associated with these outcomes were tested in univariate analysis using the log rank test. Additionally, variables that had a p-value $<0.15$ in the univariate analysis were included in a multivariate Cox proportional hazard model. Only variables that had a p-value $<0.05$ in multivariate analysis were retained in the final model. The results are reported as hazard ratios (HRs) and 95\% confidence intervals (CIs). The proportional hazards assumption was checked for each factor, and the interaction between time and non-constant covariates was introduced in the model if required. Interactions were tested between all significant factors in the Cox model. Statistical significance was defined as $\mathrm{p}<0.05$. All analyses were performed using the statistical software program SAS 9.3 (SAS Institute Inc. Cary, NC). 


\section{RESULTS}

\section{STUDY POPULATION}

A total of 93/272 (34.2\%) patients developed PCD during the follow-up period. Among them, 51/93 (54.8\%) CD patients presented a perianal lesion at diagnosis: an anal fissure was reported for $41(15.1 \%)$ patients, a perianal fistula was reported for $12(4.4 \%)$ patients, and no patient had strictures. The baseline characteristics of the CD patients who developed perianal disease are summarized in Table 1. Among the 59 patients without follow-up data, 2 patients had perianal disease at diagnosis. A complete colonoscopy at diagnosis was performed for 249 patients $(92 \%)$, and a rectal location was reported in $105(41 \%)$ patients.

\section{PERIANAL DISEASE OUTCOMES}

After a mean follow-up of 12.8 years (6.2), a total of 93 (34.2\%) patients experienced PCD. The Table 1 compared the CD characteristics between patients with and without PCD. As expected, patients with PCD were younger with more complicated luminal CD. At the end of follow-up, 15 patients still had perianal lesions: a stricture for 6 patients and fistula for 5 patients. Overall, $44 / 93$ patients $(47.3 \%)$ had anal surgery mainly for perianal fistula with a mean of $2(0.35)$ anal surgeries per patient. A stoma was required for 10 out of the 93 patients $(10.7 \%)$. In addition, patients with PCD were more likely treated with immunosuppressants (57/93 [61\%] vs 45/179 [25\%] patients, p=0.0001) and/or anti-TNF (44/93 [47\%] vs 16/179 [9\%], $\mathrm{p}=0.0001$ ). The cumulative probabilities of developing perianal CD (perianal ulceration or fistula or stricture) were $27 \%$ (23\%- 33\%) after 1 year, 31\% (26\%-37\%) after 5 years, 33\% (28\%-39\%) after 10 years, and 34\% (29\%-40\%) after 15 years (Figure 1). Among patients without perianal $\mathrm{CD}$, the cumulative probabilities of developing perianal $\mathrm{CD}$ (perianal ulceration or fistula or stricture) were $4 \%(2 \%-7 \%)$ after 1 year, $11 \%(8 \%-15 \%)$ after 5 years, $17 \%(13 \%-23 \%)$ after 10 years, and 22\% (17\%-29\%) after 15 years.

According to the multivariate analysis including age at diagnosis (age $<40$ ), colonic location (Montreal L2 and colonic location), extraintestinal manifestations, and rectal involvement (Table 1), the factors associated with an increased risk of perianal CD were extraintestinal manifestations at diagnosis $(\mathrm{HR}=2.20$ [1.3-3.7]; $\mathrm{p}=0.004)$ and rectal involvement $(\mathrm{HR}=1.58$ [1.03-2.46]; $\mathrm{p}=0.04$ ) (Table 2). The cumulative probabilities of developing perianal CD according to these 2 factors are illustrated in Figure 1. A sub-analysis of rectal involvement 
showed that the type of endoscopic lesion (aphthous lesions, superficial ulceration, deep ulcer) was associated with the risk of developing perianal lesions (Supplementary Figure 1).

\section{ANAL ULCERATION OUTCOMES}

A total of $61(23 \%)$ patients experienced anal ulceration. The cumulative probabilities of developing anal ulceration were 14\% (10\%-18\%) after 1 year, 17\% (14\%-22\%) after 5 years, 19\% (15\%-25\%) after 10 years, and 21\% (16\%-26\%) after 15 years (Figure 2). According to the multivariate analysis including age at diagnosis (age $<17)$, colonic location (Montreal L2) and extraintestinal manifestations, the factors associated with an increased risk of anal ulceration were extraintestinal manifestations $(\mathrm{HR}=2.17 \quad[1.19-3.96] ; \mathrm{p}=0.01)$ (Table 2, Figure 2).

\section{FISTULIZING PERIANAL OUTCOMES}

A total of $53(20 \%)$ patients experienced fistulizing perianal CD. The cumulative probabilities of developing fistulizing perianal CD were $11 \%(8 \%-15 \%)$ after 1 year, $16 \%(12 \%-20 \%)$ after 5 years, 19\% (14\%-24\%) after 10 years, and 20\% (16-26\%) after 15 years (Figure 3). Only isolated anal ulcerations prior to the onset of perianal fistula were taken into account to identify the predictors of fistulizing PCD. According to the multivariate analysis including colonic location, ileal location, rectal involvement, extraintestinal manifestations, and anal ulceration, the factors associated with an increased risk of fistulizing perianal CD were extraintestinal manifestations $(\mathrm{HR}=2.19$ [1.04-4.61]; $\mathrm{p}=0.04)$, rectal involvement $(\mathrm{HR}=2.22$ [1.18-4.22]; $\mathrm{p}=0.01)$ and anal ulceration $(\mathrm{HR}=2.39$ [1.25-4.56]; $\mathrm{p}=0.008)$ (Table 2). The mean time between the onset of anal ulceration and perianal fistula was 9 months $(+/-7)$. The cumulative probabilities of developing fistulizing perianal CD according to these 3 factors are illustrated in Figure 3.

\section{ANAL STRICTURE OUTCOMES}

The cumulative probabilities of developing anal stricture were $2 \%(1 \%-4 \%)$ after 1 year, $3 \%$ (2\%- $7 \%$ ) after 5 years, $4 \%(2 \%-7 \%)$ after 10 years, and 5\% (3\%-9\%) after 15 years. Anal stricture was never observed without a prior history of perianal lesion. 


\section{DISCUSSION}

In the present population-based study, $32 \%$ of patients developed perianal CD within 10 years of their diagnosis of $\mathrm{CD}$. The cumulative incidences of anal ulceration and fistulizing perianal CD were $19 \%$ after 10 years. Extraintestinal manifestations, rectal involvement and anal ulceration were associated with the onset of fistulizing perianal CD. These data should encourage practitioners to efficiently treat patients presenting with rectal involvement and/or anal ulceration to avoid the onset of fistulizing perianal disease.

The cumulative incidence rates of perianal CD after 5 and 10 years of follow-up were $29 \%$ and $32 \%$, respectively, in our study. A similar trend was observed in other population-based cohorts (5). The incidence rates of perianal fistulizing CD after 5 and 10 years of follow-up were $16 \%$ and $19 \%$, respectively, which were roughly similar to the rates in other studies ${ }^{4,14}$, 15, 29. The incidence rates of anal ulceration CD after 5 and 10 years of follow-up were $16 \%$ and $19 \%$, respectively, in our study. To the best of our knowledge, this is the first study to report the incidence rates of anal ulceration $\mathrm{CD}$. Perianal $\mathrm{CD}$ is often reduced to fistulizing perianal $\mathrm{CD}^{30,31}$, while anal ulceration $\mathrm{CD}$ is frequent and associated with more severe disease in both luminal and perianal locations ${ }^{31}$. Importantly, anal ulceration at baseline was associated with the onset of fistulizing perianal CD in our study. Of note, the incidence rate of non-fistulizing PCD was particularly high at diagnosis and stable over time, contrary to that of fistulizing PCD, which doubled during follow-up. This emphasizes the importance of physicians considering this location for decision making and the need to improve the evidence of effective treatment for this location ${ }^{32}$. 
Rectal involvement was associated with the onset of fistulizing perianal CD. Patients with rectal involvement at baseline were twice as likely to develop perianal lesions, particularly fistulizing perianal CD. A rectal location is a known risk factor for radical surgery (diverting stoma, proctectomy) or the need for repeat surgery when associated with perianal fistulizing $\mathrm{CD}^{32,33}$. The authors suggested that remission of an active rectal location concomitant to perianal fistula was important due to the association with the risk of radical surgery ${ }^{32,33}$. Importantly, the present study suggested efficiently treating patients with rectal involvement regardless of the severity of rectal disease, as this approach might prevent the occurrence of fistulizing perianal CD.

Finally, extraintestinal manifestations were associated with the onset of both anal ulceration and fistulizing perianal CD. The relationship between these two features has never been reported. A possible theory might be that perianal CD could be part of the extraintestinal manifestations. An argument found in the literature is the more frequent prevalence of these 2 diseases in Asians ${ }^{34}$.

The main strengths of this work are the sample size, the duration of follow-up and the systematic assessment of fistulizing and non-fistulizing perianal $\mathrm{CD}$ in a population-based cohort. Standardized questionnaires and recommended classifications ${ }^{27,28}$ were used. Each case was reviewed independently by expert gastroenterologists. Finally, all gastroenterologists of Brittany practising in the private or public sector participated, which reduced bias in the selection of patients. However, some limitations must be noted. There was no endoscopic review and no central reading of the endoscopy results. The diagnosis rates of anal or rectal stricture was probably underestimated. The anatomical classification of fistulas was not collected and it was not possible to differentiate rectovaginal fistulas from other types of fistulas. Perianal lesions such as skin tags, hemorrhoids were not recorded. Finally, deep and superficial ulcerations, as well as simple and complex fistulas, were not differentiated. 
In conclusion, almost one-third of patients with $\mathrm{CD}$ developed perianal lesions. Extraintestinal manifestations, rectal involvement and anal ulceration were associated with the onset of fistulizing perianal CD. Remission of these active primary lesions is needed to avoid the onset of complicated and disabling fistulizing perianal disease.

\section{REFERENCES}

1. Gomollón F, Dignass A, Annese V, Tilg H, Van Assche G, Lindsay JO, et al. 3rd European Evidence-based Consensus on the Diagnosis and Management of Crohn's Disease 2016: Part 1: Diagnosis and Medical Management. J Crohns Colitis. 2017;11:3-25.

2. Ingle SB, Loftus EV. The natural history of perianal Crohn's disease. Dig Liver Dis Off J Ital Soc Gastroenterol Ital Assoc Study Liver. 2007;39:963-9.

3. Beaugerie L, Seksik P, Nion-Larmurier I, Gendre J-P, Cosnes J. Predictors of Crohn's disease. Gastroenterology. 2006;130:650-6.

4. Makowiec F, Jehle EC, Starlinger M. Clinical course of perianal fistulas in Crohn's disease. Gut.1995;37:696-701.

5. Eglinton TW, Roberts R, Pearson J, Barclay M, Merriman TR, Frizelle FA, et al. Clinical and genetic risk factors for perianal Crohn's disease in a population-based cohort. Am J Gastroenterol. 2012;107:589-96.

6. Tarrant KM, Barclay ML, Frampton CMA, Gearry RB. Perianal disease predicts changes in Crohn's disease phenotype-results of a population-based study of inflammatory bowel disease phenotype. Am J Gastroenterol. 2008;103:3082-93.

7. Kasparek MS, Glatzle J, Temeltcheva T, Mueller MH, Koenigsrainer A, Kreis ME. Long-term quality of life in patients with Crohn's disease and perianal fistulas: influence of fecal diversion. Dis Colon Rectum. 2007;50:2067-74.

8. Mahadev S, Young JM, Selby W, Solomon MJ. Self-reported depressive symptoms and suicidal feelings in perianal Crohn's disease. Colorectal Dis Off J Assoc Coloproctology G B Irel. 2012;14:331-5.

9. Mahadev S, Young JM, Selby W, Solomon MJ. Quality of life in perianal Crohn's disease: what do patients consider important? Dis Colon Rectum. 2011;54:579-85.

10. Linares L, Moreira LF, Andrews H, Allan RN, Alexander-Williams J, Keighley MR. Natural history and treatment of anorectal strictures complicating Crohn's disease. Br J Surg. 
1988;75:653-5.

11. Brochard C, Siproudhis L, Wallenhorst T, Cuen D, d'Halluin PN, Garros A, et al. Anorectal stricture in 102 patients with Crohn's disease: natural history in the era of biologics. Aliment Pharmacol Ther. 2014;40:796-803.

12. Schwartz DA, Ghazi LJ, Regueiro M, Fichera A, Zoccali M, Ong EMW, et al. Guidelines for the multidisciplinary management of Crohn's perianal fistulas: summary statement. Inflamm Bowel Dis. 2015;21:723-30.

13. Gray BK, Lockhartmummery HE, Morson BC. Crohn's disease of the anal region. Gut. 1965;6:515-24.

14. Schwartz DA, Loftus EV, Tremaine WJ, Panaccione R, Harmsen WS, Zinsmeister AR, et al. The natural history of fistulizing Crohn's disease in Olmsted County, Minnesota. Gastroenterology. 2002;122:875-80.

15. Zhao M, Lo BZS, Vester-Andersen MK, Vind I, Bendtsen F, Burisch J. A 10-Year Follow-up Study of the Natural History of Perianal Crohn's Disease in a Danish PopulationBased Inception Cohort. Inflamm Bowel Dis. 2019;25:1227-36.

16. Park SH, Aniwan S, Scott Harmsen W, Tremaine WJ, Lightner AL, Faubion WA, et al. Update on the Natural Course of Fistulizing Perianal Crohn's Disease in a PopulationBased Cohort. Inflamm Bowel Dis. 2019;25:1054-60.

17. Rutgeerts P. Review article: treatment of perianal fistulizing Crohn's disease. Aliment Pharmacol Ther. 2004;20:106-10.

18. Sangwan YP, Schoetz DJ, Murray JJ, Roberts PL, Coller JA. Perianal Crohn's disease. Results of local surgical treatment. Dis Colon Rectum. 1996;39:529-35.

19. Wolff BG, Culp CE, Beart RW, Ilstrup DM, Ready RL. Anorectal Crohn's disease. A long-term perspective. Dis Colon Rectum. 1985;28:709-11.

20. Keighley MR, Allan RN. Current status and influence of operation on perianal Crohn's disease. Int J Colorectal Dis. 1986;1:104-7.

21. Siproudhis L, Mortaji A, Mary JY, Juguet F, Bretagne JF, Gosselin M. Anal lesions: any significant prognosis in Crohn's disease? Eur J Gastroenterol Hepatol. 1997;9:239-43.

22. Williams DR, Coller JA, Corman ML, Nugent FW, Veidenheimer MC. Anal complications in Crohn's disease. Dis Colon Rectum. 1981;24:22-4.

23. Gower-Rousseau C, Savoye G, Colombel J-F, Peyrin-Biroulet L. Are we improving disease outcomes in IBD? A view from the epidemiology side. Gut. 2014;63:1529-30.

24. Gower-Rousseau C, Vasseur F, Fumery M, Savoye G, Salleron J, Dauchet L, et al. Epidemiology of inflammatory bowel diseases: new insights from a French population-based registry (EPIMAD). Dig Liver Dis Off J Ital Soc Gastroenterol Ital Assoc Study 
Liver.2013;45:89-94.

25. Charpentier C, Salleron J, Savoye G, Fumery M, Merle V, Laberenne J-E, et al. Natural history of elderly-onset inflammatory bowel disease: a population-based cohort study. Gut. 2014;63:423-32.

26. Elliott PR, Lennard-Jones JE, Hathway N. Simple index of Crohn's disease activity. Lancet Lond Engl. 1980;1:876.

27. Irvine EJ. Usual therapy improves perianal Crohn's disease as measured by a new disease activity index. McMaster IBD Study Group. J Clin Gastroenterol. 1995;20:27-32.

28. Hughes LE. Clinical classification of perianal Crohn's disease. Dis Colon Rectum.1992;35:928-32.

29. Göttgens KWA, Jeuring SFG, Sturkenboom R, Romberg-Camps MJL, Oostenbrug LE, Jonkers DMAE, et al. Time trends in the epidemiology and outcome of perianal fistulizing Crohn's disease in a population-based cohort. Eur J Gastroenterol Hepatol. 2017;29:595-601.

30. Wallenhorst T, Brochard C, Le Balch E, Bodere A, Garros A, Merlini-1'Heritier A, et al. Anal ulcerations in Crohn's disease: Natural history in the era of biological therapy. Dig Liver Dis Off J Ital Soc Gastroenterol Ital Assoc Study Liver. 2017;49:1191-5.

31. Wallenhorst T, Brochard C, Bretagne J-F, Bouguen G, Siproudhis L. Crohn's disease: is there any link between anal and luminal phenotypes? Int J Colorectal Dis. 2016;31:307-11. 32. Sebastian S, Black C, Pugliese D, Armuzzi A, Sahnan K, Elkady SM, et al. The role of multimodal treatment in Crohn's disease patients with perianal fistula: a multicentre retrospective cohort study. Aliment Pharmacol Ther. 2018;48:941-50.

33. Yassin NA, Askari A, Warusavitarne J, Faiz OD, Athanasiou T, Phillips RKS, et al. Systematic review: the combined surgical and medical treatment of fistulising perianal Crohn's disease. Aliment Pharmacol Ther. 2014;40:741-9.

34. Kochar B, Barnes EL, Herfarth HH, Martin CF, Ananthakrishnan AN, McGovern D, et al. Asians have more perianal Crohn disease and ocular manifestations compared with white Americans. Inflamm Intest Dis. 2018;2:147-53. 


\section{Table and figure legends}

Table 1: Baseline characteristics of patients according to the occurence or not of perianal Crohn's Disease

Table 2 Risk factors associated with the risk of developing perianal Crohn's disease, anal ulceration and perianal fistulizing disease

Figure 1: Kaplan-Meier curves for overall time to perianal lesion (1A), time to perianal lesion stratified according to extraintestinal manifestation (1B), time to perianal lesion stratified according to rectal involvement (1C) and time to perianal lesion stratified according to extraintestinal manifestation and rectal involvement (1D)

Figure 2: Kaplan-Meier curves for time to anal ulceration (2A), and Cox model curve for time to anal ulceration stratified according to extraintestinal manifestation (2B),

Figure 3: Kaplan-Meier curve for overall time to perianal fistulizing disease (3A), time to perianal fistulizing disease stratified according to prior anal ulceration (3B), time to perianal fistulizing disease stratified according to extraintestinal manifestation (3C) and time to perianal fistulizing disease stratified according to rectal involvement (3D)

Supplementary Figure 1: Kaplan-Meier curves for time to perianal lesion stratified according to the presence of aphthous lesion (rectal involvement, assessed by endoscopy) (A), stratified according to the presence of superficial ulceration (rectal involvement, assessed by endoscopy) (B), and stratified according to the presence of deep ulcers (rectal involvement, assessed by endoscopy) (C) 
Table 1: Baseline characteristics of patients according to the occurence or not of perianal Crohn's Disease

\begin{tabular}{|c|c|c|c|}
\hline & $\begin{array}{c}\text { Perianal Crohn's } \\
\text { disease } \\
\text { n (\%) or median } \\
\text { [IQR 25-75] }\end{array}$ & $\begin{array}{c}\text { No Perianal } \\
\text { Crohn's Disease } \\
\text { n (\%) or median } \\
\text { [IQR 25-75] }\end{array}$ & Log rank \\
\hline $\mathrm{N}$ & $93(34.2)$ & $179(65.8)$ & \\
\hline Age at diagnosis (year) & $25.0(18.9-37.5)$ & $30.7(22.8-48.9)$ & 0.01 \\
\hline Male sex & $37(39.8)$ & 89 (49.7) & 0.11 \\
\hline Time from symptom onset to diagnosis (year) & $4(1.0-11.5)$ & $2(1.0-8.0)$ & 0.93 \\
\hline $\begin{array}{l}\text { Age at diagnosis (Montreal } \\
\text { classification)(year) }\end{array}$ & & & 0.03 \\
\hline A $1-<17$ & $18(19.3)$ & $18(10.1)$ & \\
\hline $\mathrm{A} 2-<40$ & $55(59.1)$ & $99(55.3)$ & \\
\hline A $3-\geq 40$ & $20(21.0)$ & $62(34.6)$ & \\
\hline Behaviour at diagnosis & & & 0.02 \\
\hline B1 - inflammatory disease & $47(50.5)$ & $121(67.6)$ & \\
\hline B2 - stricturing disease & $40(43.0)$ & $49(27.4)$ & \\
\hline B3 - fistulizing disease & $6(6.5)$ & $9(0.5)$ & \\
\hline Phenotype at diagnosis & & & 0.13 \\
\hline L1 - ileal disease & $11(11.8)$ & $30(16.9)$ & \\
\hline L2 - colonic disease & $41(44.1)$ & $57(32.0)$ & \\
\hline L3 - ileo-colonic disease & $41(44.1)$ & $90(50.1)$ & \\
\hline L4 - upper GI tract involvement & 22 & 39 & \\
\hline Rectal location at diagnosis & $45(50.5)$ & $60(34.4)$ & 0.0164 \\
\hline Extraintestinal manifestations at diagnosis & $19(21.6)$ & $16(9.9)$ & 0.0137 \\
\hline
\end{tabular}


Table 2 Risk factors associated with the risk of developing perianal Crohn's disease, anal ulceration and perianal fistulizing disease

\begin{tabular}{|c|c|c|c|c|c|c|c|c|c|c|c|c|}
\hline \multirow{3}{*}{ Baseline factor } & \multicolumn{4}{|c|}{ Risk factor for perianal Crohn's disease } & \multicolumn{4}{|c|}{ Risk factor for anal ulceration } & \multicolumn{4}{|c|}{ Risk factor for perianal fistulizing Crohn's disease } \\
\hline & \multicolumn{2}{|c|}{ Univariate analysis } & \multicolumn{2}{|c|}{ Multivariate analysis } & \multicolumn{2}{|c|}{ Univariate analysis } & \multicolumn{2}{|c|}{ Multivariate analysis } & \multicolumn{2}{|c|}{ Univariate analysis } & \multicolumn{2}{|c|}{ Multivariate analysis } \\
\hline & $\mathrm{p}$ & $\mathrm{HR}(95 \% \mathrm{CI})$ & $\mathrm{p}$ & $\mathrm{HR}(95 \% \mathrm{CI})$ & $\mathrm{p}$ & $\mathrm{HR}(95 \% \mathrm{CI})$ & $\mathrm{p}$ & $\mathrm{HR}(95 \% \mathrm{CI})$ & $\mathrm{p}$ & $\mathrm{HR}(95 \% \mathrm{CI})$ & $\mathrm{p}$ & $\mathrm{HR}(95 \% \mathrm{CI})$ \\
\hline $\begin{array}{l}\text { Male sex } \\
\text { Time from symptom onset to diagnosis } \\
\text { Age at diagnostis } \\
\text { A1 }-<17 \\
\text { A2 }-<40 \\
\text { A3 }-\geq 40\end{array}$ & $\begin{array}{l}Y \\
0.22 \\
0.85 \\
0.05\end{array}$ & $\begin{array}{c}1.30(0.86-1.98) \\
1.00(0.98-1.01) \\
\text { ref } \\
0.94(0.54-1.54) \\
0.59(0.33-1)\end{array}$ & $\begin{array}{c}- \\
- \\
- \\
0.29\end{array}$ & & $\begin{array}{l}r \\
0.45 \\
0.87 \\
0.04\end{array}$ & $\begin{array}{c}1.22(0.73-2.03) \\
1.00(0.98-1.02) \\
\text { ref } \\
0.51(2.7-0.95) \\
0.42(0.20-0.88)\end{array}$ & $\begin{array}{c}- \\
- \\
- \\
0.06\end{array}$ & & $\begin{array}{l}r \\
0.28 \\
0.94 \\
0.46\end{array}$ & $\begin{array}{c}1.37(0.77-2.42) \\
1.0(0.98-1.02) \\
\text { ref } \\
0.88(0.32-2.37) \\
1.32(0.56-3.16)\end{array}$ & $\begin{array}{ll}- \\
- \\
- \\
-\end{array}$ & \\
\hline $\begin{array}{l}\text { Disease Location } \\
\text { L1 - ileal disease } \\
\text { L2 - colonic disease } \\
\text { L3 - ileocolonic disease } \\
\text { L4 - upperGI tract involvement }\end{array}$ & $\begin{array}{l}0.08 \\
0.89\end{array}$ & $\begin{array}{c}0.56(0.29-1.08) \\
\text { ref } \\
0.65(0.41-1.01) \\
1.03(0.64-1.69)\end{array}$ & 0.23 & & $\begin{array}{l}0.11 \\
0.48\end{array}$ & $\begin{array}{c}0.53(0.23-1.21) \\
\text { ref } \\
0.61(0.36-1.04) \\
1.22(0.69-2.17)\end{array}$ & 0.11 & & $\begin{array}{l}0.05 \\
0.40\end{array}$ & $\begin{array}{c}0.41(0.16-1.07) \\
\text { ref } \\
0.55(0.30-1.98) \\
0.73(0.36-1.51)\end{array}$ & 0.29 & \\
\hline \begin{tabular}{|l} 
Behaviour at diagnosis \\
B1 - inflammatory disease \\
B2 - stricturing disease \\
B3 - fistulizing disease \\
\end{tabular} & 0.93 & $\begin{array}{c}\text { ref } \\
1.08(0.68-1.71) \\
0.92(0.29-2.93) \\
\end{array}$ & - & & 0.68 & $\begin{array}{c}\text { ref } \\
1.10(0.64-1.92) \\
0.46(0.06-3.36) \\
\end{array}$ & - & & 0.65 & $\begin{array}{c}\text { ref } \\
0.73(0.37-1.43) \\
0.98(0.24-4.07) \\
\end{array}$ & - & \\
\hline $\begin{array}{l}\text { Clinical features at diagnosis } \\
\text { Anal ulceration } \\
\text { Extraintestinal manifestations } \\
\end{array}$ & $\begin{array}{c}- \\
0.004 \\
\end{array}$ & $2.12(1.27-3.54)$ & $\begin{array}{c}- \\
0.004 \\
\end{array}$ & $2.20(1.30-3.70)$ & $\begin{array}{c}- \\
0.01 \\
\end{array}$ & $2.17(1.19-3.96)$ & $\begin{array}{c}- \\
0.01 \\
\end{array}$ & $2.17(1.19-3.96)$ & $\begin{array}{c}0.004 \\
0.03 \\
\end{array}$ & $\begin{array}{l}2.29(1.29-4.06) \\
2.14(1.08-4.21) \\
\end{array}$ & $\begin{array}{c}0.008 \\
0.04 \\
\end{array}$ & $\begin{array}{l}2.39(1.25-4.56) \\
2.19(1.04-4.61) \\
\end{array}$ \\
\hline $\begin{array}{l}\text { Endoscopic features at diagnosis } \\
\text { Ileal location } \\
\text { Colonic location (without rectal disease) } \\
\text { Rectal location }\end{array}$ & $\begin{array}{l}0.36 \\
0.11 \\
0.02\end{array}$ & $\begin{array}{l}0.79(0.48-1.31) \\
1.50(0.90-2.51) \\
1.62(1.06-2.50)\end{array}$ & $\begin{array}{c}- \\
0.92 \\
0.04\end{array}$ & $1.58(1.03-2.46)$ & $\begin{array}{l}0.31 \\
0.23 \\
0.20\end{array}$ & $\begin{array}{l}0.73(0.39-1.34) \\
1.45(0.78-2.69) \\
1.40(0.84-2.34)\end{array}$ & $\begin{array}{l}- \\
- \\
-\end{array}$ & & $\begin{array}{l}0.07 \\
0.15 \\
0.01\end{array}$ & $\begin{array}{c}0.52(0.26-1.06) \\
1.70(0.82-3.53) \\
2.1(1.16-3.80)\end{array}$ & $\begin{array}{l}0.49 \\
0.42 \\
0.01\end{array}$ & $2.22(1.18-4.22)$ \\
\hline
\end{tabular}



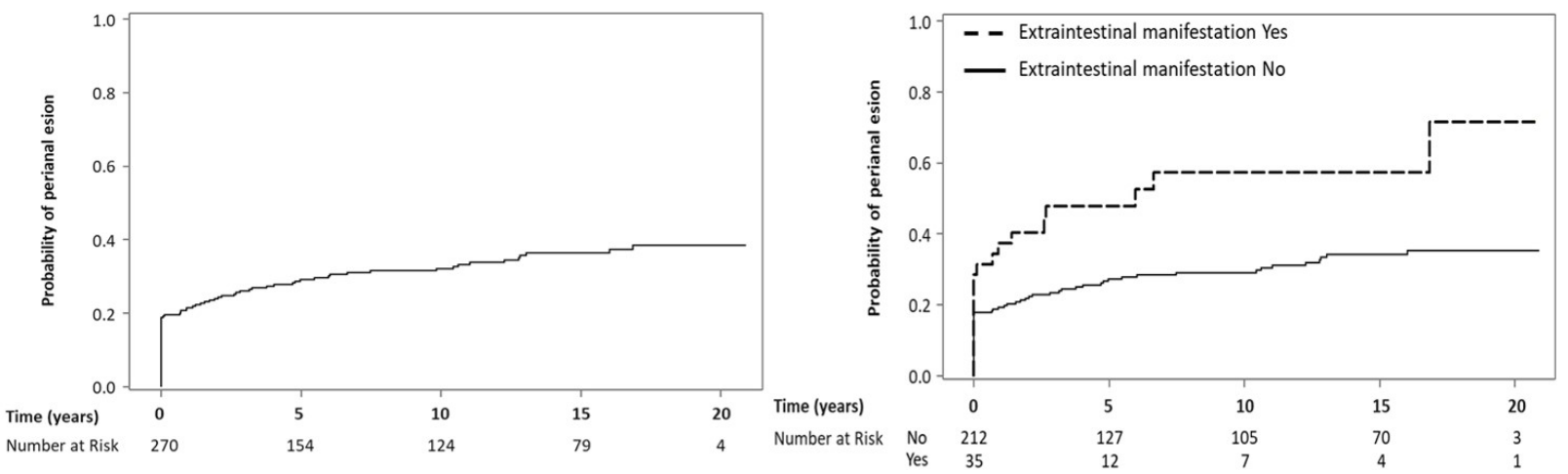

C

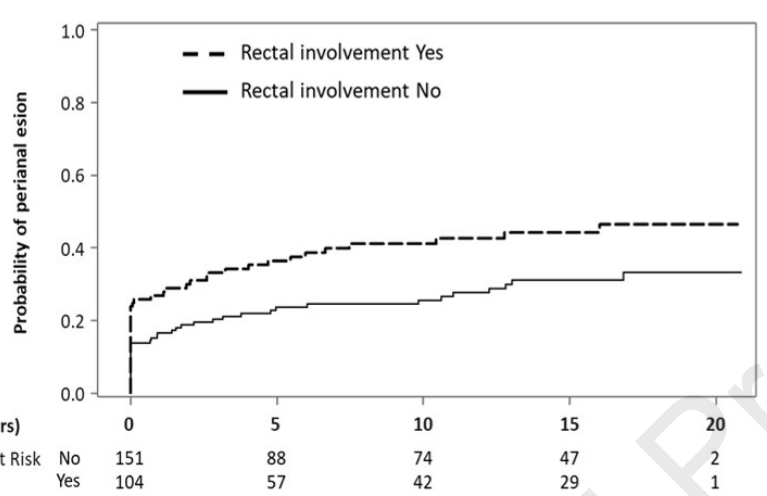

D

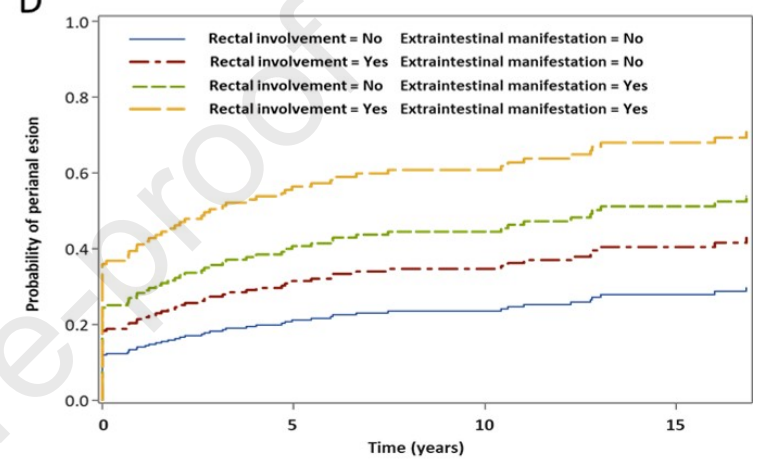

Fig. 1 


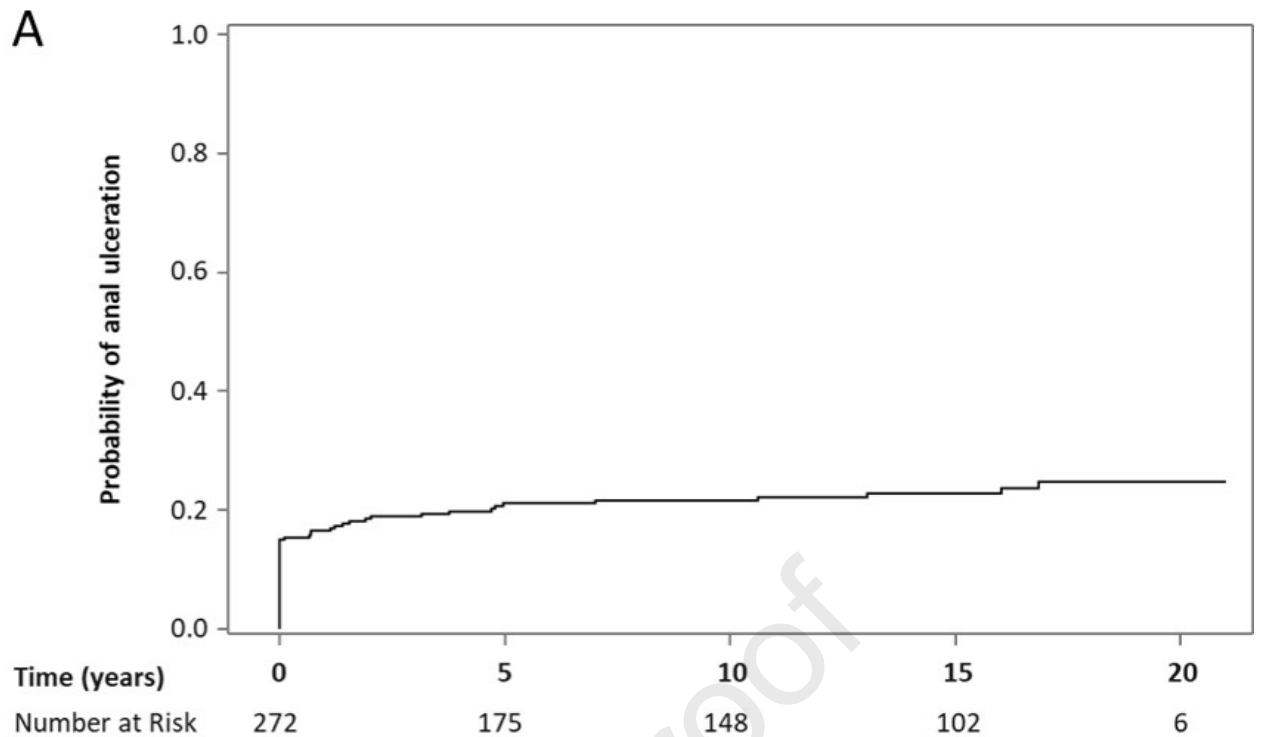

Fig. 2

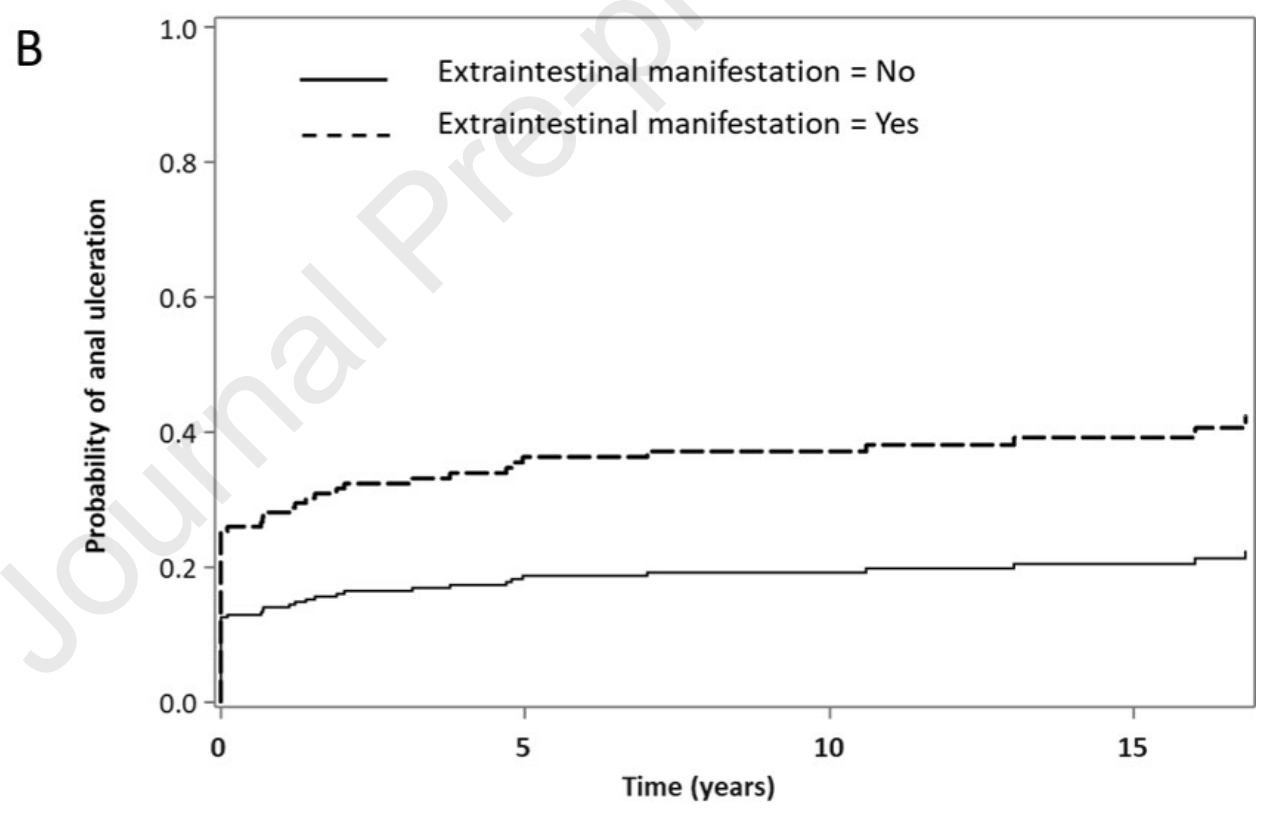


A

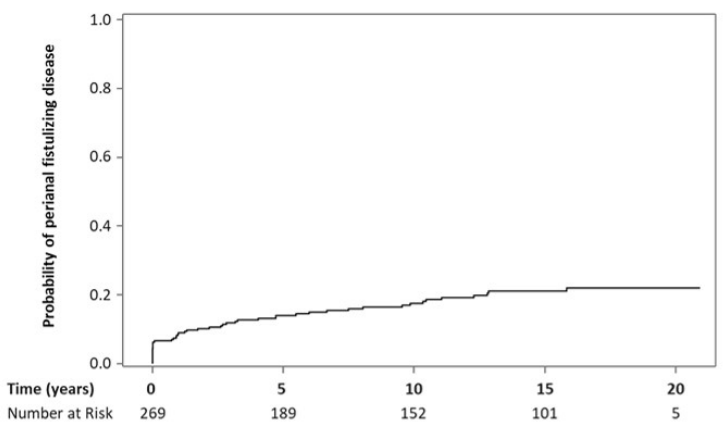

C

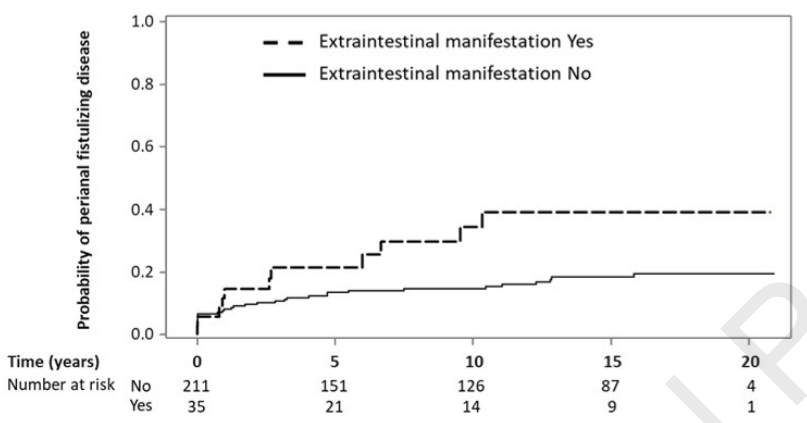

B

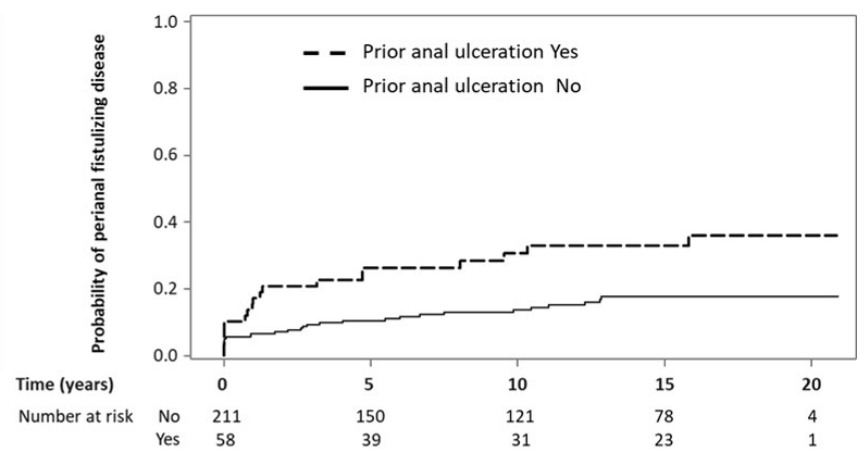

D

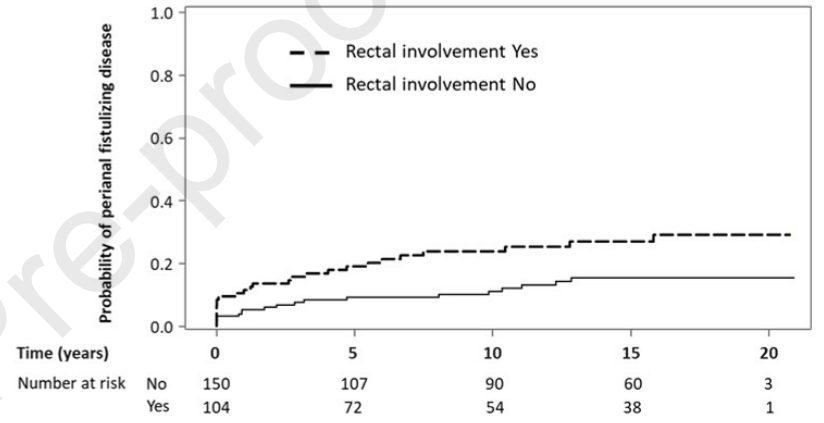

Fig. 3 
A

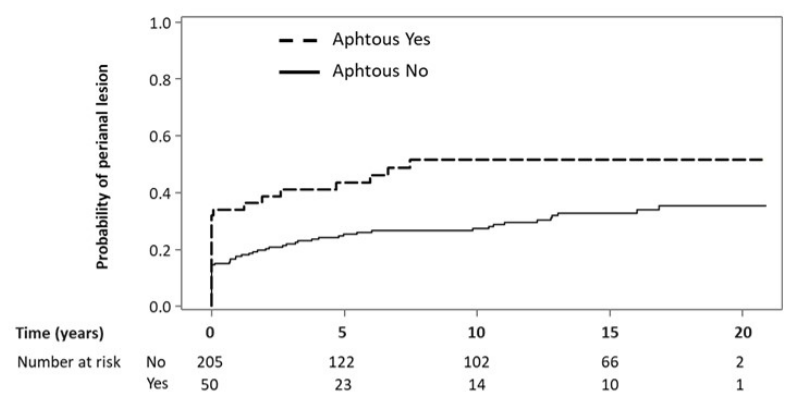

B
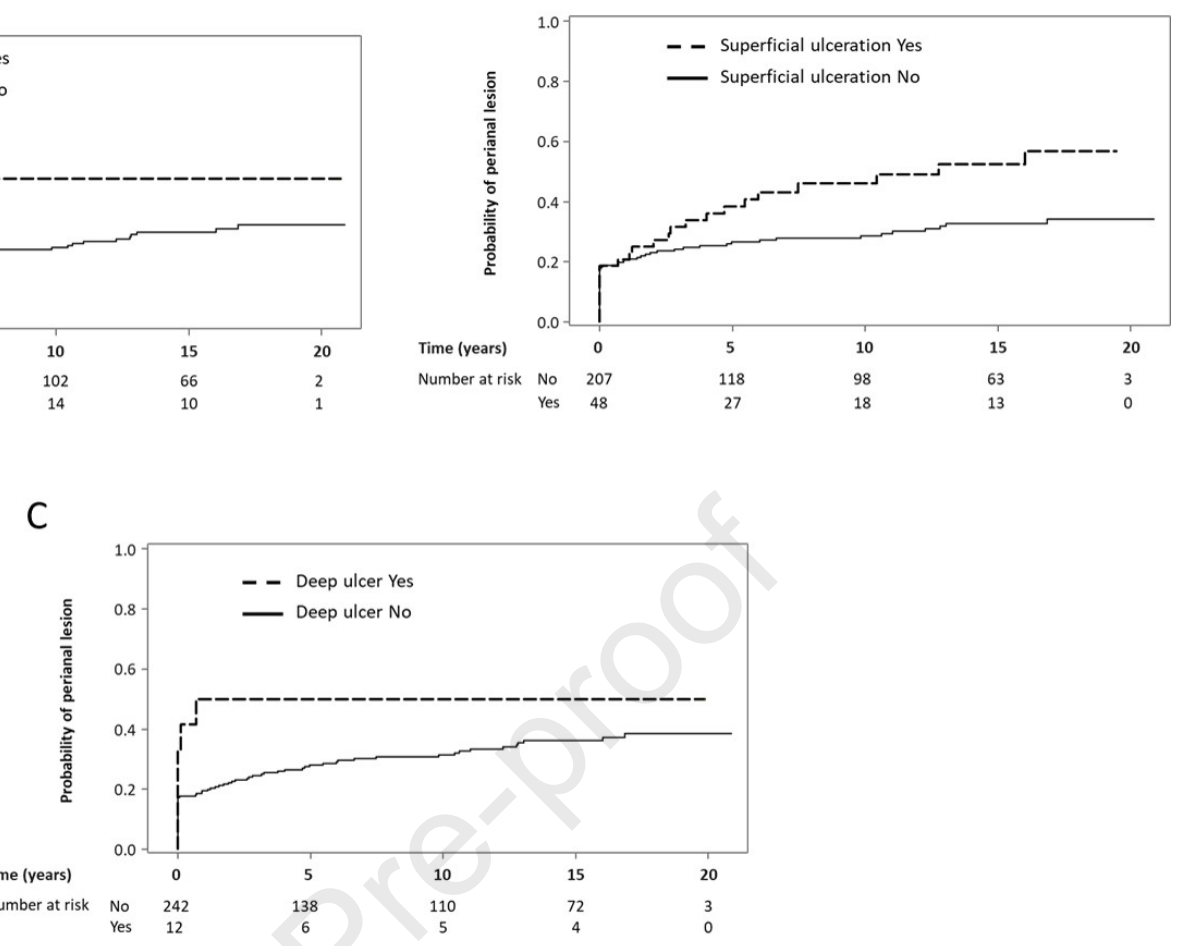

Suppl. Fig. 1 
What you need to know

BACKGROUND

The natural history of perianal Crohn's disease (PCD) is poorly described and based on retrospective studies.

FINDINGS

The cumulative probabilities of PCD occurrence were $22 \%, 29 \%$, and $32 \%$ after 1 year, 5 years, and 10 years, respectively. Extraintestinal manifestations, rectal involvement and anal ulceration were predictors of fistulizing PCD.

IMPLICATIONS FOR PATIENT CARE.

PCD is frequently observed during CD. This emphasizes the importance of physicians considering this location for decision making and the need to improve the evidence of effective treatment for this location. 